\title{
DIGITAL RESOURCES FOR MONITORING AND EVALUATING STUDENTS' OUTCOMES IN THE CONTEXT OF DISTANCE LEARNING
}

\author{
Natalia A. Biryukova ${ }^{{ }^{*}}$, Olga V. Timofeeva ${ }^{2,}$ Daria V. Ivanova ${ }^{3}$, \\ Larisa G. Zinovieva ${ }^{4}$ \\ ${ }^{1}$ Assoc. Prof., Faculty of General and Vocational Education, Mari State University, \\ RUSSIA, biryukova316@gmail.com \\ ${ }^{2}$ Assoc. Prof., Faculty of Law, Chuvash State University named after I.N. Ulyanov, \\ RUSSIAkorneeva.o@inbox.ru \\ ${ }^{3} \mathrm{PhD}$ student, Faculty of General and Vocational Education, Mari State University, \\ RUSSIA, d_a_f_f_k_a@mail.ru \\ ${ }^{4}$ Assoc. Prof., Faculty of Law, Chuvash State University named after I.N. Ulyanov, RUSSIA \\ larisa-zin-cheb@mail.ru \\ ${ }^{*}$ Corresponding Author
}

\begin{abstract}
Today Russia, like many other countries, is making a rapid transition of educational organizations from traditional forms to distance learning. Every school, university, teacher is faced with the task of urgently mastering the most efficient formats of distance teaching and learning. The authors analyzed the didactic capabilities of various digital educational platforms and Internet services for effective monitoring and evaluation of students ' learning outcomes in the context of distance learning. The study was based on a practice-oriented approach to the use of digital resources and means of evaluating students' academic achievements presented on each platform. The following issues were considered: general characteristics of the platform's capabilities, registration procedures, specific tools for evaluating learning outcomes. All digital tools for monitoring and evaluating students' learning outcomes were divided into some categories: services and tools for online testing, for evaluating written works, oral surveys, project activities, online visualization tools for assessment of students' achievements, services and tools for reflection procedures. The study resulted in recommendations for teachers on the use of digital resources for monitoring and evaluating students' learning outcomes in the context of distance learning.
\end{abstract}

Keywords: distance learning, educational platforms, monitoring and evaluation, digital resources

\section{INTRODUCTION}

The rapid transition of educational organizations to distance learning sharply raises questions about whether digital technologies are now able to offer adequate tools, resources, and services for organizing convenient and productive work in the digital environment and ensure the implementation of a full-fledged educational process in it. Currently, the world has accumulated considerable experience in implementing various distance learning platforms. They differ in methodology and reflect the characteristics of a particular country where they are practiced. However, in general, everyone recognizes that the future belongs to distance learning, not only because of the development of information and communication technologies, but also as the next stage in the development of educational systems (Toktarova, Fedorov, 2019).

Control, or verification of learning outcomes, is a mandatory component of the learning process. It takes 
place at all stages of the learning process, but it becomes especially important after studying any section of the program and completing the training stage. The essence of checking the results of training is to identify the level of knowledge acquisition by students, which should correspond to the educational standard for this program, discipline. Lomovtseva N.V. highlights the basic principles of student control that must be observed in distance learning:

- The principle of objectivity-cognitive activity in distance learning should be evaluated with minimal impact of the subjective factor;

- The principle of democracy - in distance learning, equal conditions should be created for all students who pass the control;

- The principle of mass and short-term-control with the help of remote technologies should be organized so that in as little time as possible to test the knowledge of a large number of subjects (Lomovtseva, 2009).

In general, structurally, distance learning systems, from the point of view of learning stages, can be represented by the following interrelated and interacting elements: presentation of information, consolidation of information material, knowledge control, recording of student's success, maintenance of the control system. Almost all elements, due to the integration of the system, have intellectual elements that provide fullfledged training, comparable in quality to the traditional one (Biryukova, Kolomiets, 2017).

Theoretical foundations and methods of using distance learning are described in the works of E. S. Polat, P. I. Pidkasistoy, A.V. Khutorsky. The authors analyze distance learning from the point of view of forms, methods, compare it with widespread traditional forms. A.P. Ershov, V.V. Kuznetsov, V.S. Lednev, E.I. Mashbits, I.V. Robert and others consider the influence of information technologies on the content of training. The use of information technologies for measuring and evaluating learning outcomes is considered in the works of V.I. Andreev, B.S. Gershunsky. However, the effectiveness of the use of digital resources for monitoring and evaluating student learning outcomes in the context of distance learning is currently rarely considered and little reflected in the works of scientists.

\section{MATERIALS AND METHODS}

The purpose of our work was to analyze the didactic features of digital educational platforms, modern Internet services in the context of effective evaluation of students' learning outcomes in a distance format.

There are the following categories of tools for monitoring and evaluating learning outcomes: services for organizing online testing, services and tools for evaluating written works, services and tools for evaluating oral surveys, services and tools for evaluating project activities, online visualization tools for organizing activities and evaluating students ' achievements, services and tools for organizing reflection.

Testing is one of the traditional forms of assessment. In the context of distance learning, its value increases significantly. There are enough on-line services for organizing testing. Here are examples of some of them.

- Google forms can be used in a survey or test format. Google Forms settings allow the student to immediately see which questions they answered correctly and where they made mistakes after answering the test. At the same time, the teacher has detailed analytics in his hands: he sees which tasks caused difficulties, which incorrect answers were most often chosen, and how each of the students coped.

- in Microsoft Forms, you can quickly assign grades for answering questions and provide feedback to students in various ways. You can export test results to Microsoft Excel for deeper analysis and charting, and delete or print all the answers. There are questions like: "Rating" and "Likert Scale".

- Master Test (master-test.net) is a simple constructor that can be used in training, it is free and does not contain ads. To create tests, you need to register as a teacher. If you want, you can embed a ready-made test on your website or invite participants to take a test on the service by sending them a link.

In the conditions of distance learning, the role of written works increases considerably. Written works become the main means of feedback for the teacher. The simplest options for providing completed written works to the teacher is to send them by e-mail. But it is impossible to consider this method convenient for the teacher and students, especially if the teacher conducts classes in several groups and the volume of tasks sent is significant. One of the options for simplifying interaction is the use of cloud storage. Dropbox Cloud Storage, Cloud Mail.ru, Yandex.Disk allow users to upload and store files on servers distributed on the network, and make them available to other users. Google Drive and Microsoft OneDrive cloud storage, in addition to storing and sharing files, allow you to work with documents collectively, editing them directly in the browser. 
It is much more difficult to conduct oral surveys in a distance learning format than to organize feedback through written messages. But there are subjects where it is very difficult to do without this form of assessment. And here services for on-line meetings with students can come to the rescue: zoom video conferencing and webinars service, WizIQ online training service, video conferencing system that provides the ability to record and publish webinar materials on Youtube-hangouts. When organizing the assessment of project activities of students, first of all it is necessary to use strategies of formative assessment, which allow to identify the initial experience of students; to stimulate independence and cooperation; to monitor progress; to organize a test of understanding. Services are suitable for this purpose: Google docs, Microsoft Excel online, Microsoft Word online, Online mental maps. Google Calendar, Outlook, Gantt Charts, task boards, and other project management tools.

Modern Internet services provide unique opportunities for structuring and visualizing information. Visualization techniques help support cognitive activity, see previously hidden meaning, change the perspective of vision and find a new point of view, see and establish new connections between events and objects. In the context of distance learning, these services can be very useful. For example, instead of tasks for taking notes of any primary sources, preparing reports and abstracts, students can be offered to create clusters, mental maps, time tapes, infographics, fish skeleton diagrams, Venn diagrams, SWOT analysis, etc. There are a huge number of useful, easy-to-learn services for this purpose (Razzakov, 2019).

Reflection on the subject's own activities can be organized in the form of questionnaires (Google documents, Microsoft Word online), interviews (Blogs: https://www.blogger.com, https://ru.wordpress.org/, https://www.tumblr.com/), reflection using techniques of critical thinking technology (reflexive screen, table "Plus, minus, interesting", "Six hats of thinking", composition of cinquaines) (Biryukova, Petrova, 2020).

\section{RESULTS}

At the control stage of the experiment, we identified the level of effectiveness of standard methods for monitoring and controlling students ' progress in distance learning. As a result, the level of compliance of the acquired knowledge and its effective control was below average (32\%). During the formative work in different courses and disciplines, various forms of control were applied using the digital resources described above. The results of the ascertaining experiment confirmed the effectiveness of using a variety of tools for remote monitoring and control of university students ' knowledge. The level of compliance of the acquired knowledge and its effective control increased twice $(71 \%)$.

\section{CONCLUSION}

The presented analysis of digital educational resources and services for monitoring and evaluating students ' subject achievements does not claim to be complete and accurate, since the main goal is to reveal the didactic capabilities of modern Internet services, digital educational resources in the conditions of mass transition of educational institutions to distance learning. Thus, one of the promising areas for improving the pedagogical process in the context of distance learning is the digitalization of control and evaluation of learning outcomes. The creation and use of electronic resources for monitoring and evaluating the effectiveness of students ' learning will improve the whole educational process.

\section{REFERENCE LIST}

Biryukova N.A., Kolomiets D. L., Kazarenkov V.I., Sinagatullin I.M. (2017) Preparing university educators for tutoring adult learners in distance education. Issues and Trends in Interdisciplinary Behavior and Social Science: Proceedings of the 6th International Congress on Interdisciplinary Behavior and Social Sciences (ICIBSoS 2017), Bali, Indonesia.

Biryukova N.A., Petrova T.N., Potapov A.A., Kornienko T.V. (2020) Augmented Reality in the Development of Technological Competence of Primary Schoolchildren. Abstracts \& Proceedings of INTCESS 2020 - 7th International Conference on Education and Social Sciences. Dubai, UAE.

Lomovtseva N.V. (2009). Control of educational activities in distance learning. Available at:

https://cyberleninka.ru/article/n/kontrol-uchebnoy-deyatelnosti-v-distantsionnom-obuchenii (accessed: 30.12.2020).

Razzakov, Sh. I. Control of knowledge in the system of distance learning. Available at: 
Proceedings of INTCESS 2021 8th International Conference on Education and Education of Social Sciences 18-19 January, 2021

https://moluch.ru/archive/66/10934 (accessed: 05.12.2020).

Toktarova V.I., Fedorova S.N. (2019). Adaptation of students to studying in the university electronic educational environment. Vestnik of the Mari State University. 13-3. 